\title{
Tumor Markers for Hepatocellular Carcinoma: Simple and Significant Predictors of Outcome in Patients with HCC
}

\author{
Hidenori Toyoda ${ }^{a}$ Takashi Kumada $^{a}$ Toshifumi Tada ${ }^{a}$ \\ Yasuhiro Sone $^{b}$ Yuji Kaneokac Atsuyuki Maedac

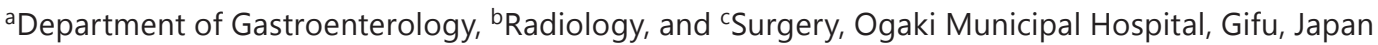

\section{Key Words}

Alpha-fetoprotein · Des-gamma-carboxy prothrombin · Hepatocellular carcinoma .

Lens culinaris agglutinin-reactive fraction of alpha-fetoprotein · Prognosis

\begin{abstract}
Background: The effectiveness of tumor markers in evaluating outcomes of patients with hepatocellular carcinoma (HCC) remains to be clarified. Summary: The usefulness of the HCC tumor markers, alpha-fetoprotein (AFP), Lens culinaris agglutinin-reactive fraction of alphafetoprotein (AFP-L3), and des-gamma-carboxy prothrombin (DCP) was reviewed. Elevations in these tumor markers at the time of HCC diagnosis correlate with disease progression as assessed by both imaging studies and pathologic examinations. The combination of these three tumor markers results in good predictive ability for patient survival after diagnosis. In addition, combination at the time of HCC diagnosis of these three tumor markers (as a measure of tumor progression) and serum albumin and bilirubin levels (as indicators of remnant liver function) can be used for HCC staging and further predicts prognosis in patients with HCC. Key Message: The prognosis of patients with HCC can be well discriminated based solely on serum markers. Staging of HCC with serum markers is objective; if stored serum samples are available, HCC stages can be standardized across different countries and time periods.
\end{abstract}

Copyright $\odot 2015$ S. Karger AG, Basel

Hidenori Toyoda, MD, PhD

Department of Gastroenterology, Ogaki Municipal Hospital

4-86 Minaminokawa, Ogaki, Gifu 503-8502 (Japan)

Tel. +81 58481 3341, E-Mail hmtoyoda@spice.ocn.ne.jp 


\section{Introduction}

Measuring levels of tumor biomarkers for hepatocellular carcinoma (HCC) is an important tool for disease management. Alpha-fetoprotein (AFP), Lens culinaris agglutinin A-reactive fraction of alpha-fetoprotein (AFP-L3), and des-gamma-carboxy prothrombin (DCP) have been established as HCC-specific tumor markers [1-14]. Although tumor marker levels are not included in the diagnostic criteria for HCC or in the screening recommendations in the guidelines of the American Association for the Study of Liver Diseases or the European Association for the Study of the Liver $[15,16]$, they provide valuable supportive information for diagnosing HCC. Furthermore, a recent study found that the combination of these three tumor markers was useful for diagnosing HCC; this combination had very high sensitivity and specificity for diagnosing HCC without the use of imaging studies [17].

The levels of AFP, AFP-L3, and DCP usually increase as HCC progresses, i.e., with increases in the size and number of HCC lesions and progression to portal vein invasion [18-22]. In addition, some studies have reported that an increase in tumor marker levels suggests a high degree of HCC malignancy regardless of morphological progression [22, 23]. Consequently, an increase in the levels of these tumor markers portends an unfavorable prognosis after initial diagnosis.

In this review, we evaluated three tumor markers of HCC, namely AFP, AFP-L3, and DCP, as indicators of tumor progression and predictors of patient outcome. In addition, we review attempts to predict prognosis solely based on serum markers.

\section{Limitations in Estimating HCC Progression by Imaging Studies and Liver Function with the Child-Pugh Classification}

The progression of HCC is usually evaluated morphologically, based on the size and number of tumors and the presence of portal vein invasion [24-26]. Such evaluations are mainly based on imaging studies prior to treatment; however, estimating tumor progression using imaging studies has several shortcomings. For example, the detectability of liver tumors by ultrasonography (US), a routine, basic imaging tool for HCC surveillance, depends on the skill of the sonographer. In addition, the detectability of liver tumors strongly depends on the resolution of the imaging modality and the quality of the equipment used for US, computed tomography (CT), or magnetic resonance imaging (MRI). Recent advances in imaging equipment such as those used in US, multidetector-row CT [27, 28], and MRI have improved the detection of hepatic nodules, including small, early-stage HCC tumors. Moreover, developments in contrast media have further enhanced the ability to detect and characterize hepatic nodules including HCC [29-36]. Thus, the number of HCCs detected will increase with advances in imaging technology, which will have the effect of upstaging HCC. Furthermore, advances in imaging techniques also improve the imaging evaluation of pathologic features of HCC including vascular invasion and macroscopic type [37-39]. This can also result in upstaging of HCC progression.

Discrepancies between findings on imaging and pathologic results are often found in patients who undergo hepatic resection. According to an annual survey of HCC by the Liver Cancer Study Group of Japan, the prevalence of HCC with portal vain invasion was $13.1 \%$ based on imaging studies and $26.0 \%$ based on pathologic analysis [40]. Using imaging studies, it is often difficult to detect microvascular invasion of HCC or minute satellite nodules; however, these entities are often found in pathologic analysis after resection, thereby indicating discrepancies in the staging of HCC progression. 


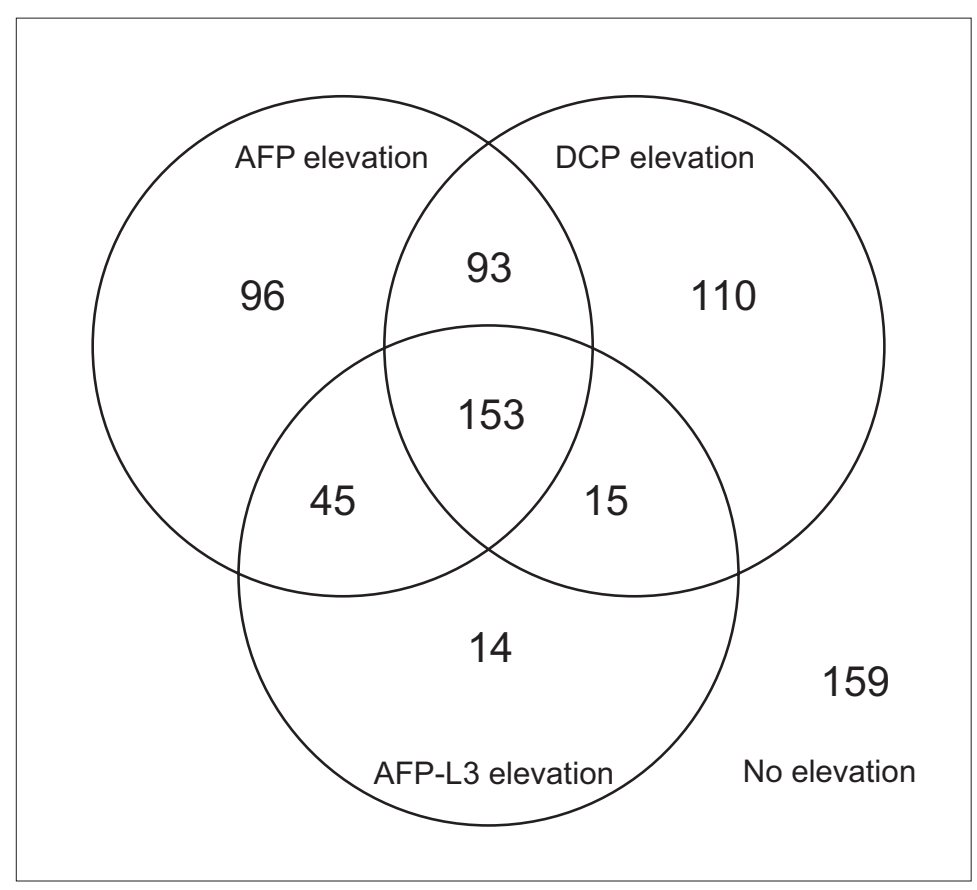

Fig. 1. Patterns of tumor marker elevation in 685 patients with hepatocellular carcinoma [43]. The tumor marker cut-off points were AFP 20 ng/dL, AFP-L3 10\%, and DCP $40 \mathrm{mAU} / \mathrm{mL}$.

Liver function in patients with HCC is usually estimated using the Child-Pugh score [41]. This score is based on patient serum albumin and bilirubin levels, prothrombin time, and the presence and controllability of ascites and hepatic encephalopathy. However, the presence and controllability of ascites and hepatic encephalopathy are often subjective. The presence of ascites varies from symptomatic ascites and ascites detected by physicians on physical examination to mild ascites only detectable by US. In addition, the controllability of ascites depends on the dose and the type of medications used. Moreover, the severity of hepatic encephalopathy may range from coma to subclinical encephalopathy.

\section{Association between Tumor Marker Levels and HCC Progression}

Several studies have reported an association between elevated tumor markers, especially AFP-L3 and DCP, and HCC progression [19, 20, 42]. Elevated AFP-L3 has been associated with microsatellite lesions and hypervascularity of HCC tumor $[18,19]$. In contrast, elevated DCP has been associated with a higher prevalence of portal vein invasion [20]. Our previous study of HCC characteristics according to elevations in various tumor markers yielded similar results [43]. Among 685 patients in whom AFP, AFP-L3, and DCP were measured at diagnosis, we found one of three tumor markers elevated in 220 patients, whereas no tumor markers were elevated in 159 patients (fig. 1). When these patients were compared (table 1), patients with elevated AFP-L3 alone had a larger number of tumors, and patients with elevated DCP alone had a higher prevalence of portal vein thrombosis. In contrast, no differences were observed in HCC progression between patients with elevated AFP alone and those with no elevated tumor markers. When elevations of these three tumor markers were considered together (table 2), there were increases in the size of the largest tumor, the number of tumors, 
Table 1. Morphological tumor progression based on imaging findings in patients with no elevations in tumor markers and those with elevation of only one tumor marker $(n=379)$ [43]

\begin{tabular}{lllll}
\hline Elevated tumor marker & $\begin{array}{l}\text { None } \\
(\mathrm{n}=159)\end{array}$ & $\begin{array}{l}\text { AFP alone } \\
(\mathrm{n}=96)\end{array}$ & $\begin{array}{l}\text { AFP-L3 alone } \\
(\mathrm{n}=14)\end{array}$ & $\begin{array}{l}\text { DCP alone } \\
(\mathrm{n}=110)\end{array}$ \\
\hline Size of largest tumor $(\mathrm{cm})^{\mathrm{a}}$ & $2.24 \pm 1.41$ & $2.17 \pm 1.20$ & $3.99 \pm 3.90$ & $3.94 \pm 3.00$ \\
Number of tumors $^{\mathrm{b}}$ & $1.42 \pm 0.97$ & $1.52 \pm 0.83$ & $2.21 \pm 1.48$ & $1.54 \pm 1.05$ \\
Portal vein thrombosis $^{\mathrm{c}}$ & $3(1.9 \%)$ & 0 & $1(7.1 \%)$ & $13(11.8 \%)$ \\
\hline
\end{tabular}

Cut-off points: AFP, $20 \mathrm{ng} / \mathrm{mL}$; AFP-L3, 10\%; DCP, $40 \mathrm{mAU} / \mathrm{mL}$.

${ }^{a}$ None vs. AFP-L3 alone, $\mathrm{p}=0.0614$; none vs. DCP alone, $\mathrm{p}<0.0001$ (Mann-Whitney U test). ${ }^{\mathrm{b}}$ None vs. AFP-L3 alone, $p=0.0075$ (Mann-Whitney U test). ${ }^{c}$ None vs. DCP alone, $p=0.0018$ (Chi-square test).

Table 2. Morphological tumor progression based on imaging findings according to the number of elevated tumor markers $(n=685)$ [43]

\begin{tabular}{lllll}
\hline $\begin{array}{l}\text { Number of elevated tumor } \\
\text { markers }\end{array}$ & $\begin{array}{l}0 \\
(\mathrm{n}=159)\end{array}$ & $\begin{array}{l}1 \\
(\mathrm{n}=220)\end{array}$ & $\begin{array}{l}2 \\
(\mathrm{n}=153)\end{array}$ & $\begin{array}{l}3 \\
(\mathrm{n}=153)\end{array}$ \\
\hline${\text { Size of largest tumor }(\mathrm{cm})^{\mathrm{a}}}^{\mathrm{a}}$ & $2.24 \pm 1.41$ & $3.18 \pm 2.61$ & $3.72 \pm 3.18$ & $5.57 \pm 3.69$ \\
Number of tumors $^{\mathrm{b}}$ & $1.42 \pm 0.97$ & $1.57 \pm 1.00$ & $2.09 \pm 2.19$ & $2.67 \pm 2.59$ \\
Portal vein thrombosis $^{\mathrm{c}}$ & $3(1.9 \%)$ & $14(6.4 \%)$ & $24(15.7 \%)$ & $50(32.7 \%)$ \\
\hline
\end{tabular}

Cut-off points: AFP, 20 ng/mL; AFP-L3, 10\%; DCP, 40 mAU/mL.

${ }^{a}$ None vs. 1 marker, none vs. 2 markers, and 2 markers vs. 3 markers, p<0.0001 (Mann-Whitney U test). ${ }^{b}$ None vs. 2 markers, $p=0.0105 ; 2$ markers vs. 3 markers, $p=0.0189$ (Mann-Whitney U test). ${ }^{\text {None vs. } 1}$ marker, $\mathrm{p}=0.0677 ; 1$ marker vs. 2 markers, $\mathrm{p}=0.0055 ; 2$ markers vs. 3 markers, $\mathrm{p}=0.0009$ (Chi-square test).

and the prevalence of portal vein thrombosis as the number of elevated tumor markers increased. Consequently, there was a correlation between the number of elevated tumor markers and the TNM tumor stage (as defined by the Liver Cancer Study of Japan [26], table 3). Thus, elevations of these tumor markers are associated with morphological progression of HCC as evaluated by imaging studies.

Elevations in tumor markers are also associated with pathologic characteristics of HCC [44]. Table 4 demonstrates the association between the number of elevated tumor markers and the size and number of HCC lesions, differentiation, growth type [40], and portal vein invasion based on pathologic examination of resected HCC specimens in 173 patients who underwent hepatectomy. In addition to increases in tumor size, there were increases in the prevalence of moderately or poorly differentiated HCC, HCC with infiltrative growth, and microscopic portal vein invasion as the number of elevated tumor markers increased, all of which indicate the progressive nature of HCC. Thus, these tumor markers reflect HCC progression in terms of pathologic features as well as findings on imaging studies.

\section{Predicting Survival of Patients with HCC Based on Tumor Markers}

Figure 2 shows the survival rates after HCC diagnosis according to elevations in each tumor marker. The survival rate in patients with any elevated tumor marker was significantly lower than that in patients without any elevated tumor markers $(\mathrm{p}<0.0001)$. Lower survival 
Table 3. Association between TNM tumor stage ${ }^{a}$ and the number of elevated tumor markers $(n=685)$ [43]

\begin{tabular}{lcccc}
\hline $\begin{array}{l}\text { Number of elevated } \\
\text { tumor markers }\end{array}$ & $\begin{array}{l}\text { Stage I } \\
(\mathrm{n}=182)\end{array}$ & $\begin{array}{l}\text { Stage II } \\
(\mathrm{n}=261)\end{array}$ & $\begin{array}{l}\text { Stage III } \\
(\mathrm{n}=147)\end{array}$ & $\begin{array}{l}\text { Stage IV } \\
(\mathrm{n}=95)\end{array}$ \\
\hline None $(\mathrm{n}=159)$ & $69(43.4 \%)$ & $68(42.8 \%)$ & $19(11.9 \%)$ & $3(1.9 \%)$ \\
1 marker $(\mathrm{n}=220)$ & $61(27.7 \%)$ & $101(45.9 \%)$ & $45(20.5 \%)$ & $13(5.9 \%)$ \\
2 markers $(\mathrm{n}=153)$ & $44(28.8 \%)$ & $51(33.3 \%)$ & $34(22.2 \%)$ & $24(15.7 \%)$ \\
3 markers $(\mathrm{n}=153)$ & $8(5.2 \%)$ & $41(26.8 \%)$ & $49(32.0 \%)$ & $55(36.0 \%)$ \\
\hline
\end{tabular}

Cut-off points: AFP, $20 \mathrm{ng} / \mathrm{mL}$; AFP-L3, 10\%; DCP, $40 \mathrm{mAU} / \mathrm{mL}$.

aTNM stage as defined by Liver Cancer Study of Japan [26].

Table 4. Morphological tumor progression based on pathologic examination according to the number of elevated tumor markers $(n=173)$ [44]

\begin{tabular}{|c|c|c|c|c|}
\hline $\begin{array}{l}\text { Number of elevated tumor } \\
\text { markers }\end{array}$ & $\begin{array}{l}0 \\
(\mathrm{n}=47)\end{array}$ & $\begin{array}{l}1 \\
(n=57)\end{array}$ & $\begin{array}{l}2 \\
(n=38)\end{array}$ & $\begin{array}{l}3 \\
(n=31)\end{array}$ \\
\hline Size of largest tumor $(\mathrm{cm})^{\mathrm{a}}$ & $2.25 \pm 1.09$ & $2.96 \pm 2.02$ & $3.75 \pm 2.88$ & $4.87 \pm 3.74$ \\
\hline Multiple tumors & 7 (14.9\%) & 7 (12.3\%) & $8(21.1 \%)$ & $7(22.6 \%)$ \\
\hline $\begin{array}{l}\text { Moderate or poor } \\
\text { differentiation }{ }^{b}\end{array}$ & 21 (44.7\%) & $30(52.6 \%)$ & $29(76.3 \%)$ & $29(93.5 \%)$ \\
\hline Infiltrative growth type ${ }^{c}$ & $3(6.4 \%)$ & $4(7.0 \%)$ & $4(10.5 \%)$ & $11(35.5 \%)$ \\
\hline Portal vein invasion ${ }^{\mathrm{d}}$ & $3(6.4 \%)$ & $5(8.8 \%)$ & $11(28.9 \%)$ & $21(67.7 \%)$ \\
\hline
\end{tabular}

Cut-off points: AFP, $20 \mathrm{ng} / \mathrm{mL}$; AFP-L3, 5\%; DCP, $40 \mathrm{mAU} / \mathrm{mL}$.

${ }^{\mathrm{a}} \mathrm{p}<0.0001$ (Jonckheere-Terpstra test), ${ }^{\mathrm{b}, \mathrm{d}} \mathrm{p}<0.0001,{ }^{\mathrm{c}} \mathrm{p}=0.0010$ (Cochran-Armitage test).

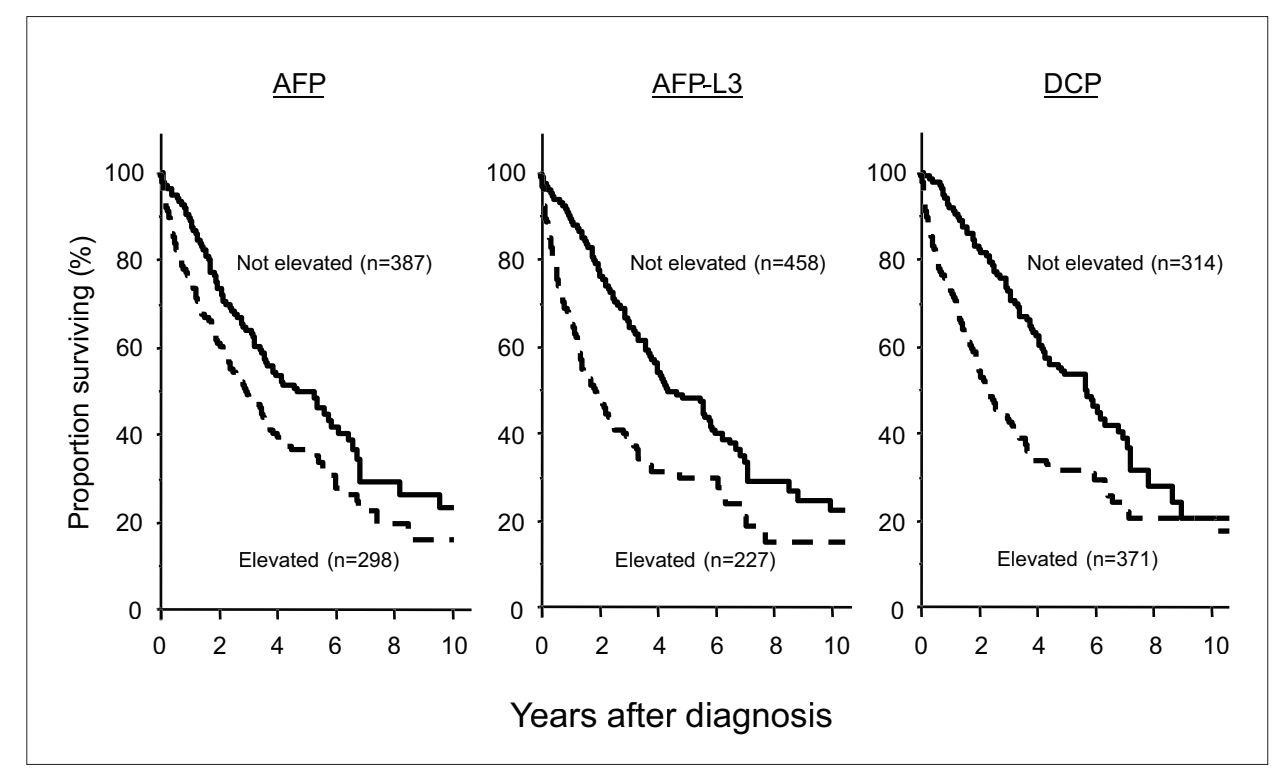

Fig. 2. Patient survival according to the presence of tumor marker elevation. $p<0.0001$ for all comparisons. 


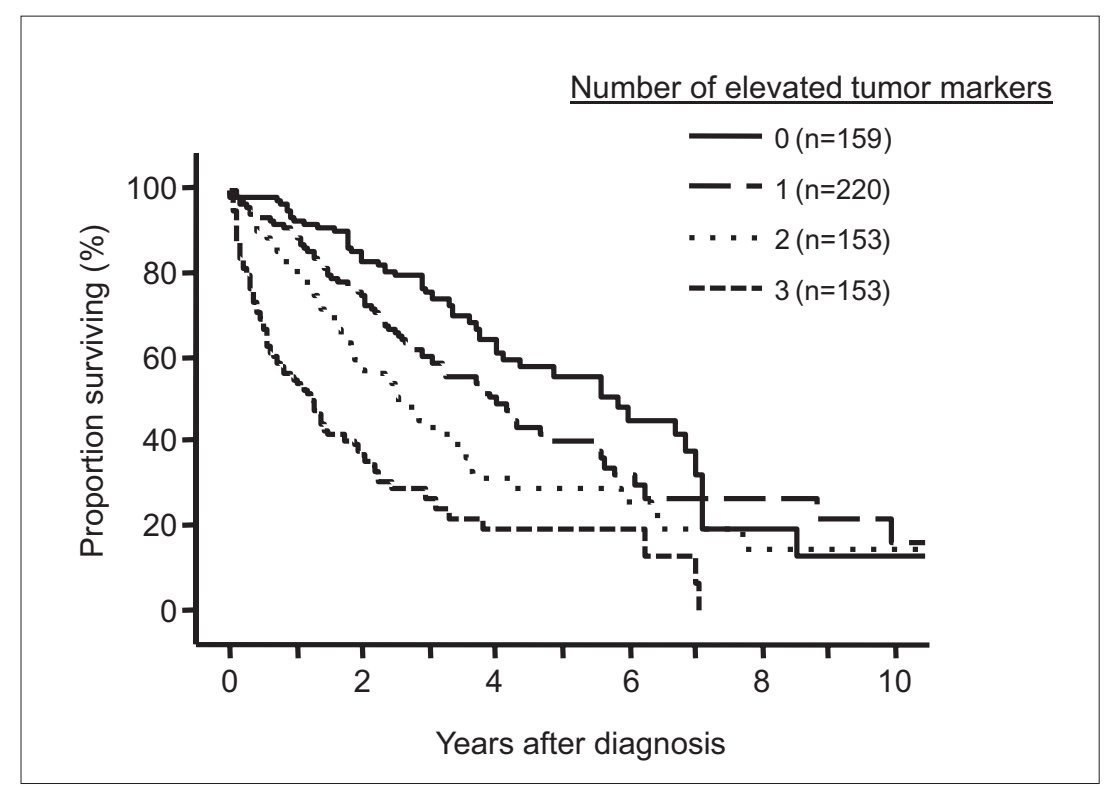

Fig. 3. Patient survival according to the number of the elevated tumor markers [43]. 0 vs. $1, p=0.0181 ; 1$ vs. $2, p=0.0141 ; 2$ vs. $3, p<0.0001$.

rates in patients with elevated AFP-L3 or DCP at diagnosis may result from the progressive nature of HCC in these patients. Indeed, previous studies reported that AFP-L3 elevation is associated with a higher rate of recurrence [45] and a lower survival rate $[45,46]$. In addition, DCP elevation has been associated with higher recurrence and lower survival rates $[47,48]$.

Despite the weak association between HCC progression and AFP elevation, the survival rate is lower in patients with AFP elevation. Previous studies have found a higher incidence of HCC in patients with elevated AFP $[49,50]$. Therefore, AFP elevation may reflect the potential risk of HCC development in the background liver more strongly than it reflects HCC progression.

Elevations of combinations of these three tumor markers further discriminate the survival of patients with HCC (fig. 3). According to our previous analysis, the number of elevated tumor markers is associated with patient survival after diagnosis independent of remnant liver function (i.e., Child-Pugh class) and treatment modalities used [43].

\section{Staging of HCC Patients Based Solely on Serum Markers}

Since liver function, in addition to tumor extension, is an important factor affecting the prognosis of patients with HCC, several prognostic staging systems for HCC that incorporate parameters indicating both tumor progression and remnant liver function have been proposed [51-56]. Only a few staging systems include tumor markers as factors [51, 53]; however, as shown in this review, tumor markers are associated with survival in HCC patients.

As described above, Child-Pugh classification is not perfectly objective as an estimate of liver function. In a previous study, Tateishi et al. proposed a new staging system for HCC in which only serum albumin and bilirubin values are used as indicators of remnant liver function [56]; this approach allows for objective and standardized evaluation of remnant liver function. A more recent study also reported that the combination of serum bilirubin and 
Table 5. Calculation of the BALAD score

\begin{tabular}{lllll}
\hline Contribution to BALAD score & 0 & 1 & 2 & 3 \\
Bilirubin-albumin score & A & B & C & \\
Number of elevated tumor markers & 0 & 1 & 2 & 3 \\
\hline
\end{tabular}

The BALAD score is the sum of the remnant liver function score (bilirubin-albumin score) and tumor progression score (number of elevated tumor markers), e.g., a bilirubinalbumin score of B contributes 1 point, so a patient with two elevated tumor markers and a bilirubin-albumin score of $B$ has a BALAD score of $2+1=3$.

albumin shows better discriminatory ability than Child-Pugh class for prognosis in patients with HCC [57]. The question therefore arises, to what extent does the combination of serum values of AFP, AFP-L3, and DCP (as tumor progression indicators) and bilirubin and albumin (as remnant liver function indicators) constitute an objective prognostic staging system for patients with HCC?

A staging system for HCC that is based solely on serum markers, not involving imaging or pathologic or clinical evaluations, was developed and its ability to discriminate patient survival was evaluated [58]. Among factors reflecting remnant liver function, serum albumin levels of above $3.5 \mathrm{~g} / \mathrm{dL}, 2.8-3.5 \mathrm{~g} / \mathrm{dL}$, or below $2.8 \mathrm{~g} / \mathrm{dL}$ were scored as 0,1 , or 2 , respectively. Serum total bilirubin levels of below $1.0 \mathrm{mg} / \mathrm{dL}, 1.0-2.0 \mathrm{mg} / \mathrm{dL}$, or above $2.0 \mathrm{mg} / \mathrm{dL}$ were scored as 0,1 , or 2, respectively. Liver function was then categorized by the sum of these two scores as A ( 0 or 1 ), B (2 or 3), or C (4). As a tumor progression factor, we simply used the number of elevated tumor markers. The HCC staging score based on these laboratory data was calculated as the sum of the tumor progression factor and liver function factor, as shown in table 5. We referred to this as the BALAD score, based on the first letter of each of the five serum markers (Bilirubin, Albumin, Lens culinaris agglutinin A-reactive fraction of AFP, AFP, and DCP). The BALAD score discriminates patient survival after diagnosis well, and is comparable to staging systems based on imaging studies and Child-Pugh class [58]. In addition, a recent study showed that this score could predict the prognosis of patients with HCC in different countries despite differences in HCC etiology [59].

\section{Advantages and Disadvantages of Evaluating Patients with HCC Based on Serum Markers Alone}

The advantage of this staging system based solely on serum markers is its objectivity. The results are numerical and are not influenced by the quality of imaging technology, operator skill, or subjective evaluation. Since this staging can be based on one serum sample and uses one standard, HCC stage can be standardized across countries and time periods (if stored serum samples are available). In contrast, a staging system based on serum markers alone is not applicable to diagnosis, treatment planning, or treatment itself because of the lack of imaging information; imaging studies are mandatory for these purposes. This staging system is not intended to be a treatment allocation system: it is solely for staging HCC to predict patient outcomes. In addition, this serum marker-based staging system is not applicable for patients being administered drugs that can influence the levels of serum markers or in the presence of disorders that can influence the levels of these serum markers. 


\section{Perspective}

Although biomarkers are not widely accepted as important clinical tools, they contribute valuable information for the management of patients with HCC, with regards to surveillance, diagnosis, evaluation of treatment efficacy, and prediction of outcomes. Their usefulness does not vary by country or HCC etiology. In addition to the HCC tumor markers reviewed here (AFP, AFP-L3, and DCP), many serum biomarkers, including glypican-3, insulin-like growth factor, osteopontin, golgi protein-73, and squamous cellular carcinoma antigen, have been investigated as candidates for HCC tumor markers [60-66]. These novel potential HCC tumor markers, alone or in combination with other markers, will further contribute to the management of patients with HCC. In addition, several serum markers or indices of liver fibrosis have been reported as risk factors of HCC development or prognostic factors in HCC [67-69]. These markers of liver fibrosis may further improve the prediction of outcome in patients with HCC.

\section{References}

1 Tsukuma H, Hiyama T, Tanaka S, Nakao M, Yabuuchi T, Kitamura T, Nakanishi K, Fujimoto I, Inoue A, Yamazaki H, Kawashima T: Risk factors for hepatocellular carcinoma among patients with chronic liver disease. N Engl J Med 1993;328:1797-1801.

2 Oka H, Tamori A, Kuroki T, Kobayashi K, Yamamoto S: Prospective study of alpha-fetoprotein in cirrhotic patients monitored for development of hepatocellular carcinoma. Hepatology 1994;19:61-66.

3 Di Bisceglie AM, Sterling RK, Chung RT, Everhart JE, Dienstag JL, Bonkovsky HL, Wright EC, Everson GT, Lind say KL, Lok AS, Lee WM, Morgan TR, Ghany MG, Gretch DR, HALT-C Trial Group: Serum alpha-fetoprotein levels in patients with advanced hepatitis C: results from the HALT-C Trial. J Hepatol 2005;43:434441.

4 Taketa K, Sekiya C, Namiki M, Akamatsu K, Ohta Y, Endo Y, Kosaka K: Lectin-reactive profiles of alpha-fetoprotein characterizing hepatocellular carcinoma and related conditions. Gastroenterology 1990;99:508518.

5 Taketa K, Endo Y, Sekiya C, Tanikawa K, Koji T, Taga H, Satomura S, Matsuura S, Kawai T, Hirai H: A collaborative study for the evaluation of lectin-reactive $\alpha$-fetoproteins in early detection of hepatocellular carcinoma. Cancer Res 1993;53:5419-5423.

6 Shimizu K, Taniichi T, Satomura S, Matsuura S, Taga H, Taketa K: Establishment of assay kits for the determination of microheterogeneities of alpha-fetoprotein using lectin-affinity electrophoresis. Clin Chim Acta 1993;214:3-12.

7 Oka H, Saito A, Ito K, Kumada T, Satomura S, Kasugai H, Osaki Y, Seki T, Kudo M, Tanaka M, Collaborative Hepato-Oncology Study Group of Japan: Multicenter prospective analysis of newly diagnosed hepatocellular carcinoma with respect to the percentage of Lens culinaris agglutinin-reactive alpha-fetoprotein. J Gastroenterol Hepatol 2001;16:1378-1383.

8 Liebman HA, Furie BC, Tong MJ, Blanchard RA, Lo KJ, Lee SD, Coleman MS, Furie B: Des-gamma-carboxy (abnormal) prothrombin as a serum marker of primary hepatocellular carcinoma. N Engl J Med 1984;310:1427-1431.

9 Okuda H, Obata H, Nakanishi T, Furukawa R, Hashimoto E: Production of abnormal prothrombin (desgamma-carboxy prothrombin) by hepatocellular carcinoma. A clinical and experimental study. J Hepatol 1987;4:357-363.

10 Mita Y, Aoyagi Y, Yanagi M, Suda T, Suzuki Y, Asakura H: The usefulness of determining des-gamma-carboxy prothrombin by sensitive enzyme immunoassay in the early diagnosis of patients with hepatocellular carcinoma. Cancer 1998;82:1643-1648.

11 Okuda H, Nakanishi T, Takatsu K, Saito A, Hayashi N, Watanabe K, Magario N, Yokoo T, Naraki T: Measurement of serum levels of des-gamma-carboxy prothrombin in patients with hepatocellular carcinoma by a revised enzyme immunoassay kit with increased sensitivity. Cancer 1999;85:812-818.

12 Nomura F, Ishijima M, Kuwa K, Tanaka N, Nakai T, Ohnishi K: Serum des-gamma-carboxy prothrombin levels determined by a new generation of sensitive immunoassays in patients with small-sized hepatocellular carcinoma. Am J Gastroenterol 1999;94:650-654.

13 Okuda H, Nakanishi T, Takatsu K, Saito A, Hayashi N, Takasaki K, Takenami K, Yamamoto M, Nakano M: Serum levels of des-gamma-carboxy prothrombin measured using the revised enzyme immunoassay kit with increased sensitivity in relation to clinicopathologic features of solitary hepatocellular carcinoma. Cancer 2000;88:544-549.

14 Fujiyama S, Tanaka M, Maeda S, Ashihara H, Hirata R, Tomita K: Tumor markers in early diagnosis, followup and management of patients with hepatocellular carcinoma. Oncology 2002;62(Suppl 1):57-63. 
15 Bruix J, Sherman M, American Association for the Study of Liver Diseases: Management of hepatocellular carcinoma: an update. Hepatology 2011;53:1020-1022.

16 European Association for the Study of the Liver, European Organisation for Research and Treatment of Cancer: EASL-EORTC clinical practice guidelines: management of hepatocellular carcinoma. J Hepatol 2012;56:908-943.

17 Johnson PJ, Pirrie SJ, Cox TF, Berhane S, Teng M, Palmer D, Morse J, Hull D, Patman G, Kagebayashi C, Hussain S, Graham J, Reeves H, Satomura S: The detection of hepatocellular carcinoma using a prospectively developed and validated model based on serological biomarkers. Cancer Epidemiol Biomarkers Prev 2014;23:144-153.

18 Kumada T, Nakano S, Takeda I, Kiriyama S, Sone Y, Hayashi K, Katoh H, Endoh T, Sassa T, Satomura S: Clinical utility of Lens culinaris agglutinin-reactive alpha-fetoprotein in small hepatocellular carcinoma: special reference to imaging diagnosis. J Hepatol 1999;30:125-130.

19 Tada T, Kumada T, Toyoda H, Kiriyama S, Sone Y, Tanikawa M, Hisanaga Y, Kitabatake S, Kuzuya T, Nonogaki K, Shimizu J, Yamaguchi A, Isogai M, Kaneoka Y, Washizu J, Satomura S: Relationship between Lens culinaris agglutinin-reactive $\alpha$-fetoprotein and pathologic features of hepatocellular carcinoma. Liver Int 2005;25:848-853.

20 Koike Y, Shiratori Y, Sato S, Obi S, Teratani T, Imamura M, Yoshida H, Shiina S, Omata M: Des-gamma-carboxy prothrombin as a useful predisposing factor for the development of portal venous invasion in patients with hepatocellular carcinoma: a prospective analysis of 227 patients. Cancer 2001;91:561-569.

21 Toyoda H, Kumada T, Osaki Y, Oka H, Kudo M: Role of tumor markers in assessment of tumor progression and prediction of outcomes in patients with hepatocellular carcinoma. Hepatol Res 2007;37(Suppl 2):S166-S171.

22 Yamamoto K, Imamura H, Matsuyama Y, Hasegawa K, Beck Y, Sugawara Y, Makuuchi M, Kokudo N: Significance of alpha-fetoprotein and des- $\gamma$-carboxy prothrombin in patients with hepatocellular carcinoma undergoing hepatectomy. Ann Surg Oncol 2009;16:2795-2804.

23 Yamanaka J, Yamanaka N, Nakasho K, Tanaka T, Ando T, Yasui C, Kuroda N, Takata M, Maeda S, Matsushita K, Uematsu K, Okamoto E: Clinicopathologic analysis of stage II-III hepatocellular carcinoma showing early massive recurrence after liver resection. J Gastroenterol Hepatol 2000;15:1192-1198.

24 International Union Against Cancer (UICC): Liver. In: Sobin LH, Wittekind CH, eds. TNM Classification of Malignant Tumours. 6th ed. New York, NY: Wiley, 2002: 81-83.

25 Vauthey JN, Lauwers GY, Esnaola NF, Do KA, Belghiti J, Mirza N, Curley SA, Ellis LM, Regimbeau JM, Rashid A, Cleary KR, Nagorney DM: Simplified staging for hepatocellular carcinoma. J Clin Oncol 2002;20:1527-1536.

26 Liver Cancer Study Group of Japan: The general rules for the clinical and pathological study of primary liver cancer (English Ed.) Kaneraha \& Co. Ltd: Tokyo, 2003.

27 Kawata S, Murakami T, Kim T, Hori M, Federle MP, Kumano S, Sugihara E, Makino S, Nakamura H, Kudo M: Multidetector CT: diagnostic impact of slice thickness on detection of hypervascular hepatocellular carcinoma. AJR Am J Roentgenol 2002;179:61-66.

28 Ichikawa T, Erturk SM, Araki T: Multiphasic contrast-enhanced multidetector-row CT of liver: contrast-enhancement theory and practical scan protocol with a combination of fixed injection duration and patients' body-weight-tailored dose of contrast material. Eur J Radiol 2006;58:165-176.

29 Numata K, Fukuda H, Miwa H, Ishii T, Moriya S, Kondo M, Nozaki A, Morimoto M, Okada M, Takebayashi S, Maeda S, Nozawa A, Nakano M, Tanaka K: Contrast-enhanced ultrasonography findings using a perflubutane-based contrast agent in patients with early hepatocellular carcinoma. Eur J Radiol 2014;83:95-102.

30 Quaia E, De Paoli L, Angileri R, Pizzolato R, Cabibbo B, Cova MA: Evidence of diagnostic enhancement pattern in hepatocellular carcinoma nodules $\leq 2 \mathrm{~cm}$ according to the AASLD/EASL revised criteria. Abdom Imaging 2013;38:1245-1253.

31 Di Martino M, De Filippis G, De Santis A, Geiger D, Del Monte M, Lombardo CV, Rossi M, Corradini SG, Mennini G, Catalano C: Hepatocellular carcinoma in cirrhotic patients: prospective comparison of US, CT and MR imaging. Eur Radiol 2013;23:887-896.

32 Hamm B, Staks T, Mühler A, Bollow M, Taupitz M, Frenzel T, Wolf KJ, Weinmann HJ, Lange L: Phase I clinical evaluation of Gd-EOB-DTPA as a hepatobiliary MR contrast agent: safety, pharmacokinetics, and MR imaging. Radiology 1995;195:785-792.

33 Vogl TJ, Kümmel S, Hammerstingl R, Schellenbeck M, Schumacher G, Balzer T, Schwarz W, Müller PK, Bechstein WO, Mack MG, Söllner 0, Felix R: Liver tumors: comparison of MR imaging with Gd-EOB-DTPA and Gd-DTPA. Radiology 1996;200:59-67.

34 Kim SH, Kim SH, Lee J, Kim MJ, Jeon YH, Park Y, Choi D, Lee WJ, Lim HK: Gadoxetic acid-enhanced MRI versus triple-phase MDCT for the preoperative detection of hepatocellular carcinoma. AJR Am J Roentgenol 2009;192:1675-1681.

35 Van Beers BE, Pastor CM, Hussain HK: Primovist, Eovist: what to expect? J Hepatol 2012;57:421-429.

36 Reimer P, Rummeny EJ, Shamsi K, Balzer T, Daldrup HE, Tombach B, Hesse T, Berns T, Peters PE: Phase II clinical evaluation of Gd-EOB-DTPA: dose, safety aspects, and pulse sequence. Radiology 1996;199:177183.

37 Shirabe K, Kajiyama K, Abe T, Sakamoto S, Fukuya T, Akazawa K, Morita K, Maehara Y: Predictors of microscopic portal vein invasion by hepatocellular carcinoma: measurement of portal perfusion defect area ratio. J Gastroenterol Hepatol 2009;24:1431-1436.

38 Tada T, Kumada T, Toyoda H, Ito T, Sone Y, Kaneoka Y, Maeda A, Okuda S, Otobe K, Takahashi K: Utility of contrast-enhanced ultrasound with perflubutane for diagnosing the macroscopic type of small nodular hepatocellular carcinomas. Eur Radiol 2014;24:2157-2166. 
39 Tada T, Kumada T, Toyoda H, Ito T, Sone Y, Okuda S, Ogawa S, Igura T, Imai Y: Diagnostic accuracy for macroscopic classification of nodular hepatocellular carcinoma: comparison of gadolinium ethoxybenzyl diethylenetriamine pentaacetic acid-enhanced magnetic resonance imaging and angiography-assisted computed tomography. J Gastroenterol 2015;50:85-94.

40 Ikai I, Kudo M, Arii S, Omata M, Kojiro M, Sakamoto M, Takayasu K, Hayashi N, Makuuchi M, Matsuyama Y, Monden M: Report of the 18th follow-up survey of primary liver cancer in Japan. Hepatol Res 2010;40:1043-1059.

41 Pugh RN, Murray-Lyon IM, Dawson JL, Pietroni MC, Williams R: Transection of the oesophagus for bleeding oesophageal varices. Br J Surg 1973;60:646-649.

42 Kaibori M, Ishizaki M, Matsui K, Kwon AH: Predictors of microvascular invasion before hepatectomy for hepatocellular carcinoma. J Surg Oncol 2010;102:462-468.

43 Toyoda H, Kumada T, Kiriyama S, Sone Y, Tanikawa M, Hisanaga Y, Yamaguchi A, Isogai M, Kaneoka Y, Washizu J: Prognostic significance of simultaneous measurement of three tumor markers in patients with hepatocellular carcinoma. Clin Gastroenterol Hepatol 2006;4:111-117.

44 Toyoda H, Kumada T, Tada T, Niinomi T, Ito T, Kaneoka Y, Maeda A: Prognostic significance of a combination of pre- and post-treatment tumor markers for hepatocellular carcinoma curatively treated with hepatectomy. J Hepatol 2012;57:1251-1257.

45 Hayashi K, Kumada T, Nakano S, Takeda I, Sugiyama K, Kiriyama S, Sone Y, Miyata A, Shimizu H, Satomura S: Usefulness of measurement of Lens culinaris agglutinin-reactive fraction of alpha-fetoprotein as a marker of prognosis and recurrence of small hepatocellular carcinoma. Am J Gastroenterol 1999;94:3028-3033.

46 Yamashita F, Tanaka M, Satomura S, Tanikawa K: Prognostic significance of Lens culinaris agglutinin Areactive alpha-fetoprotein in small hepatocellular carcinomas. Gastroenterology 1996;111:996-1001.

47 Toyoda H, Kumada T, Kaneoka Y, Osaki Y, Kimura T, Arimoto A, Oka H, Yamazaki O, Manabe T, Urano F, Chung H, Kudo M, Matsunaga T: Prognostic value of pretreatment levels of tumor markers for hepatocellular carcinoma on survival after curative treatment of patients with HCC. J Hepatol 2008;49:223-232.

48 Kobayashi M, Ikeda K, Kawamura Y, Yatsuji H, Hosaka T, Sezaki H, Akuta N, Suzuki F, Suzuki Y, Saitoh S, Arase Y, Kumada H: High serum des-gamma-carboxy prothrombin level predicts poor prognosis after radiofrequency ablation of hepatocellular carcinoma. Cancer 2009;115:571-580.

49 Tateyama M, Yatsuhashi H, Taura N, Motoyoshi Y, Nagaoka S, Yanagi K, Abiru S, Yano K, Komori A, Migita K, Nakamura M, Nagahama H, Sasaki Y, Miyakawa Y, Ishibashi H: Alpha-fetoprotein above normal levels as a risk factor for the development of hepatocellular carcinoma in patients infected with hepatitis $\mathrm{C}$ virus. J Gastroenterol 2011;46:92-100.

50 Kumada T, Toyoda H, Kiriyama S, Tanikawa M, Hisanaga Y, Kanamori A, Tada T, Tanaka J, Yoshizawa H: Predictive value of tumor markers for hepatocarcinogenesis in patients with hepatitis C virus. J Gastroenterol 2011;46:536-544.

51 The Cancer of the Liver Italian Program (CLIP) Investigators: A new prognostic system for hepatocellular carcinoma: a retrospective study of 435 patients: the Cancer of the Liver Italian Program (CLIP) investigators. Hepatology 1998;28:751-755.

52 Llovet JM, Brú C, Bruix J: Prognosis of hepatocellular carcinoma: the BCLC staging classification. Semin Liver Dis 1999;19:329-338.

53 Chevret S, Trinchet JC, Mathieu D, Rached AA, Beaugrand M, Chastang C: A new prognostic classification for predicting survival in patients with hepatocellular carcinoma. Groupe d'Etude et de Traitement du Carcinome Hépatocellulaire. J Hepatol 1999;31:133-141.

54 Leung TW, Tang AM, Zee B, Lau WY, Lai PB, Leung KL, Lau JT, Yu SC, Johnson PJ: Construction of the Chinese University Prognostic Index for hepatocellular carcinoma and comparison with the TNM staging system, the Okuda staging system, and the Cancer of the Liver Italian Program staging system: a study based on 926 patients. Cancer 2002;94:1760-1769.

55 Kudo M, Chung H, Haji S, Osaki Y, Oka H, Seki T, Kasugai H, Sasaki Y, Matsunaga T: Validation of a new prognostic staging system for hepatocellular carcinoma: the JIS score compared with the CLIP score. Hepatology 2004;40:1396-1405.

56 Tateishi R, Yoshida H, Shiina S, Imamura H, Hasegawa K, Teratani T, Obi S, Sato S, Koike Y, Fujishima T, Makuuchi M, Omata M: Proposal of a new prognostic model for hepatocellular carcinoma: an analysis of 403 patients. Gut 2005;54:419-425.

57 Johnson PJ, Berhane S, Kagebayashi C, Satomura S, Teng M, Reeves HL, O’Beirne J, Fox R, Skowronska A, Palmer D, Yeo W, Mo F, Lai P, Inarrairaegui M, Chan SL, Sangro B, Miksad R, Tada T, Kumada T, Toyoda H: Assessment of liver function in patients with hepatocellular carcinoma: a new evidence based approachthe 'ALBI' grade. J Clin Oncol (in press).

58 Toyoda H, Kumada T, Osaki Y, Oka H, Urano F, Kudo M, Matsunaga T: Staging hepatocellular carcinoma by a novel scoring system (BALAD score) based on serum markers. Clin Gastroenterol Hepatol 2006;4:15281536.

59 Fox R, Berhane S, Teng M, Cox T, Tada T, Toyoda H, Kumada T, Kagebayashi C, Satomura S, Johnson PJ: Biomarker-based prognosis in hepatocellular carcinoma: validation and extension of the BALAD model. Br J Cancer 2014;110:2090-2098.

60 Hippo Y, Watanabe K, Watanabe A, Midorikawa Y, Yamamoto S, Ihara S, Tokita S, Iwanari H, Ito Y, Nakano K, Nezu J, Tsunoda H, Yoshino T, Ohizumi I, Tsuchiya M, Ohnishi S, Makuuchi M, Hamakubo T, Kodama T, Aburatani H: Identification of soluble NH2-terminal fragment of glypican-3 as a serological marker for early-stage hepatocellular carcinoma. Cancer Res 2004;64:2418-2423. 
61 Capurro M, Wanless IR, Sherman M, Deboer G, Shi W, Miyoshi E, Filmus J: Glypican-3: a novel serum and histochemical marker for hepatocellular carcinoma. Gastroenterology 2003;125:89-97.

62 Nakatsura T, Yoshitake Y, Senju S, Monji M, Komori H, Motomura Y, Hosaka S, Beppu T, Ishiko T, Kamohara H, Ashihara H, Katagiri T, Furukawa Y, Fujiyama S, Ogawa M, Nakamura Y, Nishimura Y: Glypican-3, overexpressed specifically in human hepatocellular carcinoma, is a novel tumor marker. Biochem Biophys Res Commun 2003;306:16-25.

63 Tsai JF, Jeng JE, Chuang LY, You HL, Wang LY, Hsieh MY, Chen SC, Chuang WL, Lin ZY, Yu ML, Dai CY: Serum insulin-like growth factor-II as a serologic marker of small hepatocellular carcinoma. Scand J Gastroenterol 2005;40:68-75.

64 Kim J, Ki SS, Lee SD, Han CJ, Kim YC, Park SH, Cho SY, Hong YJ, Park HY, Lee M, Jung HH, Lee KH, Jeong $\mathrm{SH}$ : Elevated plasma osteopontin levels in patients with hepatocellular carcinoma. Am J Gastroenterol 2006;101:2051-2059.

65 Marrero JA, Romano PR, Nikolaeva O, Steel L, Mehta A, Fimmel CJ, Comunale MA, D’Amelio A, Lok AS, Block TM: GP73, a resident Golgi glycoprotein, is a novel serum marker for hepatocellular carcinoma. J Hepatol 2005;43:1007-1012.

66 Giannelli G, Marinosci F, Trerotoli P, Volpe A, Quaranta M, Dentico P, Antonaci S: SCCA antigen combined with alpha-fetoprotein as serologic markers of HCC. Int J Cancer 2005;117:506-509.

67 Yamasaki K, Tateyama M, Abiru S, Komori A, Nagaoka S, Saeki A, Hashimoto S, Sasaki R, Bekki S, Kugiyama Y, Miyazoe Y, Kuno A, Korenaga M, Togayachi A, Ocho M, Mizokami M, Narimatsu H, Yatsuhashi H: Elevated serum levels of Wisteria floribunda agglutinin-positive human Mac-2 binding protein predict the development of hepatocellular carcinoma in hepatitis C patients. Hepatology 2014;60:1563-1570.

68 Tamaki N, Kurosaki M, Matsuda S, Muraoka M, Yasui Y, Suzuki S, Hosokawa T, Ueda K, Tsuchiya K, Nakanishi H, Itakura J, Takahashi Y, Asahina Y, Izumi N: Non-invasive prediction of hepatocellular carcinoma development using serum fibrosis marker in chronic hepatitis C patients. J Gastroenterol 2014;49:1495-1503.

69 Toyoda H, Kumada T, Tada T, Kaneoka Y, Maeda A: A laboratory marker, FIB-4 index, as a predictor for longterm outcomes of hepatocellular carcinoma patients after curative hepatic resection. Surgery (in press). 